\title{
Evaluation of Reintervention Frequency in Patients Undergoing Interventional and/or Surgical Treatment for Aortic Coarctation
}

\author{
(1) Cansu Özdemiral1, (1) Timur Meşe2, (1) Murat Muhtar Yılmazer², (1) Mustafa Karaçelik2, \\ (D) Engin Gerçeker², (1) Cüneyt Zihni2
}

${ }^{1}$ İzmir Katip Çelebi University, Atatürk Training and Research Hospital, Clinic of Pediatrics, İzmir, Turkey

2University of Health Sciences Turkey, İzmir Dr. Behçet Uz Children Training and Research Hospital, Clinic of Pediatrics and Pediatric Surgery

\begin{abstract}
Objectives: The aim of the study was to evaluate the frequency of reintervention in patients who underwent interventional and/or surgical treatment for aortic coarctation, and to determine the causative factors.

Materials and Methods: Our study included 85 patients who were treated with the diagnosis of aortic coarctation between 2011 and 2018. Data processing, echocardiography, cardiac catheterization-angiocardiography, and operative records of the patients were retrospectively evaluated.

Results: As the initial treatment choice, 38 (44\%) patients underwent percutaneous interventional procedure [31 (36\%) patients balloon angioplasty and $7(8 \%)$ patients stent implantation, respectively], while $47(55 \%)$ patients were treated surgically. Of the treated patients, 17 (28\%) developed recoarctation. Among the patients who were treated and followed up, $20 \%$ of those who underwent balloon angioplasty developed recoarctation, while $8 \%$ of those who underwent surgery developed recoarctation $(\mathrm{p}=0.02)$. Seven patients who underwent stent implantation had no recoarctation throughout the follow-up period. The presence of discrete coarctation $(\mathrm{p}=0.00)$, high pre-procedural peak-to-peak pressure gradient
\end{abstract}

Address for Correspondence: : Cansu Özdemiral, İzmir Katip Çelebi University, Atatürk Training and Research Hospital, Clinic of Pediatrics, İzmir, Turkey

e-mail: dr.cansukafes@gmail.com ORCID: orcid.org/0000-0001-9911-0469

Received: 31.12.2020 Accepted: 24.02.2021

Cite this article as: Özdemiral C, Meşe T, Yılmazer MM, Karaçelik M, Gerçeker E, Zihni C. Evaluation of Reintervention Frequency in Patients Undergoing Interventional and/or Surgical Treatment for Aortic Coarctation. EJCM 2021;9(1):61-69.

DOI: 10.32596/ejcm.galenos.2020-12-067

${ }^{\circ}$ Copyright 2021 by Heart and Health Foundation of Turkey (TÜSAV) / E Journal of Cardiovascular Medicine published by Galenos Publishing House. 


\begin{abstract}
$(\mathrm{p}=0.00)$ and high post-procedural peak-to-peak pressure gradient $(\mathrm{p}=0.00)$, and performing balloon angioplasty $(\mathrm{p}=0.02)$ as the initial treatment were evaluated as the factors leading to recoarctation development.

Conclusion: It was concluded that the best treatment modality would be preferred based on the characteristics of the patient because of the lower incidence of recoarctation in surgical treatment but fewer procedure-related complications in interventional treatments.
\end{abstract}

Keywords: Coarctation of the aorta, balloon angioplasty, surgery, pediatrics, stent

\section{Introduction}

Aortic coarctation (CoA) accounts for $4-6 \%$ of all congenital heart diseases, with an incidence of 3 per 10,000 births $^{(1,2)}$. CoA is a congenital obstructive anomaly of the aortic lumen. It may coexist with other cardiac anomalies such as bicuspid aortic valve (BAV), aortic arch hypoplasia, patent ductus arteriosus (PDA), ventricular septal defect (VSD), and atrial septal defect (ASD) ${ }^{(3)}$.

Various symptoms can occur depending on the severity of coarctation and concomitant cardiac anomalies. The clinical presentation varies greatly depending on age ${ }^{(4)}$. Neonates may develop heart failure with the closure of the ductus arteriosus, and children may exhibit signs of getting exhausted quickly, leg pain with exercise, chest pain, and hypertension. Since the clinical manifestation may be insignificant in patients without severe coarctation, the diagnosis may be delayed until adolescence or even adulthood.

CoA is diagnosed with physical examination findings (systemic hypertension, difference between upper and lower limb blood pressure, absence of femoral artery pulse) and using one or more of the techniques of echocardiographic examination, cardiac computarized tomography, cardiac magnetic resonance imaging (cMRI), cardiac catheterization, and angiography.

In the literature, there are different options regarding the treatment of CoA Mostly preferred treatment options are surgical repair, transcatheter balloon angioplasty, and transcatheter stent implantation depending on the anatomy of coarctation, age of the patient, size of the patient, and other comorbidities. For neonates and young infants, surgery is accepted as the initial intervention of choice for significant CoA. Transcatheter balloon angioplasty for native discrete $\mathrm{CoA}$ is for children over one year old and is also preferred in younger patients with recoarctation, and in neonates and young infants, this option is mainly reserved in patients with associated ventricular dysfunction to get them stabilized for definitive surgical repair. The transcatheter stent implantation is a preferred treatment method for native and recurrent $\mathrm{CoA}$ in older children, adolescents, and adults ${ }^{(5,6)}$.

Surgical resection and end-to-end anastomosis, extended resection and end-to-end anastomosis, subclavian flap aortoplasty, prosthetic "patch plasty", and Dacron patch/tube graft are used.

In the literature, there are different results regarding the treatment of $\mathrm{CoA}$ in terms of treatment success and incidence of recoarctation by the patient's age, characteristics of the coarctation, the treatment method chosen, and patients' follow-up period ${ }^{(7-10)}$.

\section{Materials and Methods}

The study included patients $(\mathrm{n}=85)$ who were followedup by the Pediatric Cardiology Clinic of University of Health Sciences Turkey, Dr. Behçet Uz Children's Diseases and Surgery Training and Research Hospital and who underwent interventional procedures and/or were operated for CoA by cardiovascular surgery between 2011 and 2018.

\title{
Özdemiral et al. Surgical Treatment for CoA
}


Patients' echocardiography, cardiac catheterizationangiocardiography, and surgical records were evaluated retrospectively.

\section{Design of the Study}

The study included patients between the ages of 0 and 18 years with a cardiac index of $\geq 3 \mathrm{~L} / \mathrm{min} / \mathrm{m}^{2}$, who were diagnosed with $\mathrm{CoA}$ and who underwent cardiac catheterization. Having congenital cyanotic and complex heart disease and the presence of intracardiac tumors were considered as exclusion criteria.

In our study, patients' demographics such as age, gender, body weight and age at diagnosis, as well as conventional measurements obtained by 2-dimensional, M-Mode and Doppler echocardiography (left ventricular wall thickness and diameters, aortic valve, ascending aorta, aortic arch, and isthmus diameters, left ventricular fractional shortening and ejection fraction values, Doppler echocardiographic peak instantaneous pressure gradient of the coarctation area) were retrospectively obtained from hospital records. The diameters of the isthmus, descending aorta, coarctation area (mm, Z-score) of patients measured during the catheter-angiography were recorded. During the hemodynamic study, peak-to-peak pressure gradients at the coarctation level were recorded in pull-back pressure recordings. The data on the surgical technique used were obtained from the operative records of the pediatric cardiovascular surgery clinic.

In our study, patients were grouped as those who underwent an interventional procedure (balloon angioplasty, stent) and those who underwent coarctation surgery. And, patients who were retreated were evaluated by their treatment modalities (Figure 1).

\section{Statistical Analysis}

SPSS 20.0 (Statistical Package for Social Sciences for Windows Software) was used for the statistical analysis of the data. The Kolmogorov-Smirnov test was employed to evaluate the normality of the distribution of quantitative variables. The Student's t-test was used for normally distributed samples, while the Mann-Whitney U test was performed to compare the data of non-normally distributed variables. The chi-square analysis was used for the comparison of categorical variables, while the Wilcoxon signed-rank test was utilized for the comparison of pre- and post-treatment variables. A p-value of $<0.05$ was considered as statistically significant.

\section{Results}

Of the patients included in our study, $55(65 \%)$ were male and $30(35 \%)$ were female, with a male to female

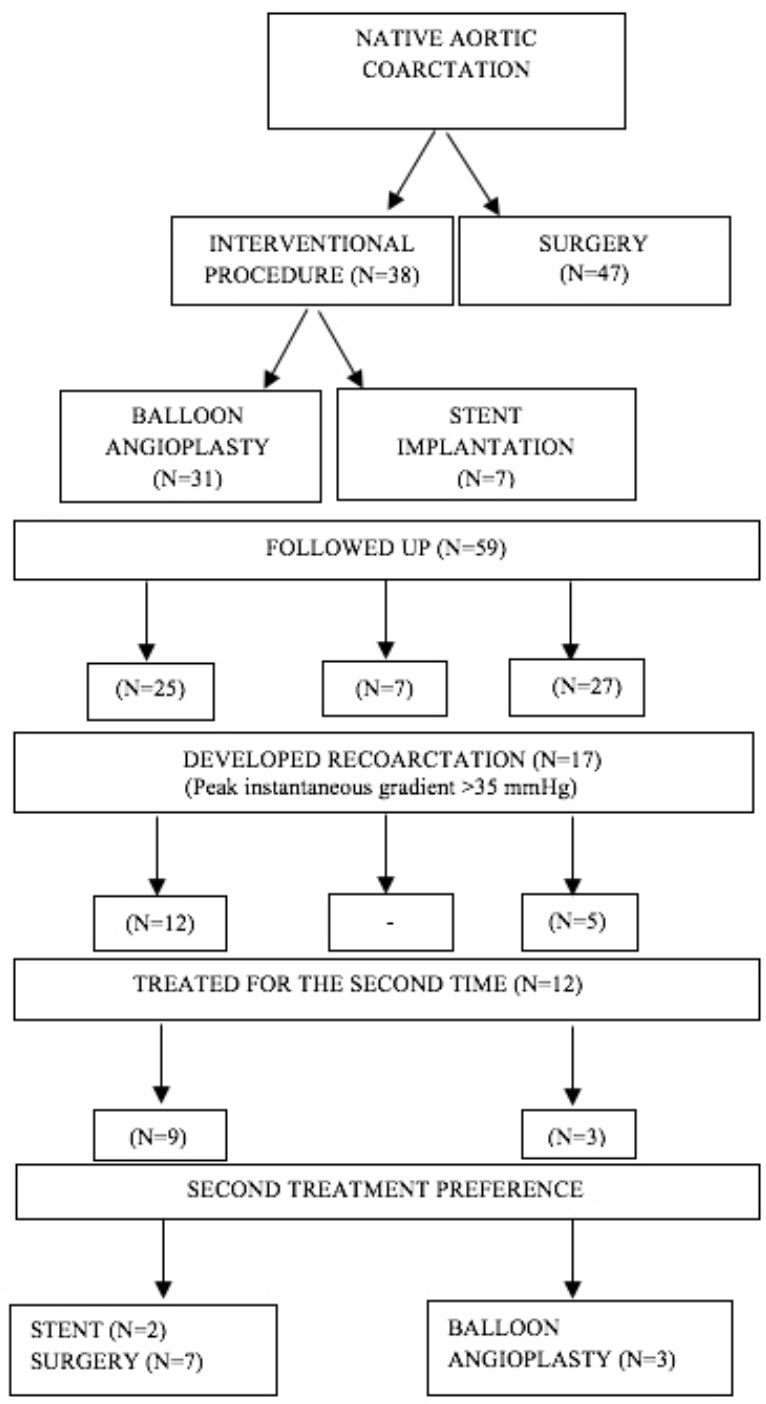

Figure 1. Patients who were retreated were evaluated by their treatment modalities 
ratio of 1.8. The ages of the patients at the time of diagnosis ranged from 7 days to 14 years (median age: 3 months). The median bodyweight of the patients at the time of diagnosis was $5 \mathrm{~kg}$ (range: 3-17 kg). One patient had the diagnosis of Turner syndrome.

Of a total of 85 patients, $21(24.7 \%)$ had preductal, $58(68 \%)$ had juxtaductal, and $6(7 \%)$ had postductal coarctation. Of the patients, $45(52 \%)$ were diagnosed with isolated AC, and 40 (47\%) had additional cardiac defects; 20 (23\%) had PDA, 17 (20\%) had BAV, 11 had (12\%) VSD, 9 (10\%) had ASD, and two had aberrant right subclavian artery. None of the patients had cardiac dysfunction.

In the coarctation area, the pre-procedural peak instantaneous pressure gradient measured by echocardiography was $45.0 \pm 16.4 \mathrm{mmHg}$, while the peak-to-peak pressure gradient determined by cardiac catheterization was $31.0 \pm 14.7 \mathrm{mmHg}$.

It was found that the initial treatment choice was surgical repair for neonates, while it was balloon angioplasty for patients older than one year (Table 1). All of the patients who underwent stent implantation were older than 10 years.

Balloon angioplasty resulted in a decrease of $22.6 \pm 11.7$ $\mathrm{mmHg}(\mathrm{p}<0.05)$ in the peak-to-peak pressure gradient at the coarctation level, while a decrease of $23 \mathrm{mmHg}(14-40$ $\mathrm{mmHg})(\mathrm{p}=0.02)$ was achieved in those who underwent stent implantation; there was no significant difference between the two treatment modalities in terms of efficacy in the early period (Table 2).

In patients treated surgically, the peak instantaneous pressure gradient achieved in the left subclavian artery distal decreased from the median value of $40 \mathrm{mmHg}$ (30$50 \mathrm{mmHg})$ to $12 \mathrm{mmHg}(10-19 \mathrm{mmHg})(\mathrm{p}<0.05)$.

The type and location of coarctation were significantly different in terms of the initial treatment choice. Juxtaductal coarctation was more frequent in patients who underwent interventional procedures compared to those treated surgically $(\mathrm{p}<0.05)$. All patients with preductal coarctation underwent surgical procedures, and of the six patients with postductal coarctation, five patients were treated interventionally and one surgically. Tubular

Table 1. Distribution of treatment modalities by age groups of patients

\begin{tabular}{|l|l|l|}
\hline Age groups & \multicolumn{2}{|c|}{ Total } \\
\hline 1-29 days & $\mathbf{n}$ & $\%^{*}$ \\
\hline 1-12 months & 23 & 27.1 \\
\hline 1-5 years & 37 & 43.5 \\
\hline 5-10 years & 8 & 9.4 \\
\hline >10 years & 8 & 9.4 \\
\hline
\end{tabular}

Balloon angioplasty

$\%$ **

8.7

45.9

28

16

4

\section{Surgical treatment}

$\%$ **

91.3

54.1

4

16

4

n: Number

${ }^{*}$ Percentages among all patients in the study, ${ }^{* *}$ Percentages within the same age group

Table 2. Cardiac catheterization measurements and treatment distributions

\begin{tabular}{|l|l|l|l|}
\hline & $\begin{array}{l}\text { Balloon angioplasty }(\mathbf{n = 3 1}) \\
\text { Mean } \pm \text { SD }\end{array}$ & $\begin{array}{l}\text { Aortic stent }(\mathbf{n = 7}) \\
\text { Mean } \pm \text { SD }\end{array}$ & p-value \\
\hline Isthmus diameter Z-score & $-0.30 \pm 0.93$ & $0.23 \pm 0.58$ & 0.128 \\
\hline Coarctation area, $(\mathrm{mm})$ & $5.1 \pm 2.5$ & $8.5 \pm 4.5$ & 0.022 \\
\hline Pre-procedural peak-to-peak gradient, $(\mathrm{mmHg})$ & $30.8 \pm 13.3$ & $32.3 \pm 22.2$ & 0.794 \\
\hline Post-procedural peak-to-peak gradient, $(\mathrm{mmHg})$ & $8.2 \pm 7.2$ & $2.7 \pm 6.5$ & 0.022 \\
\hline SD: Standard deviation, $n:$ Number & & & \\
\hline
\end{tabular}


coarctation was more frequent in the surgical group than in the interventional group $(\mathrm{p}<0.05)$. Of the patients with discrete coarctation, $66 \%$ underwent balloon angioplasty. Those with a Z-score below -2 for aortic (ascending, arcus, isthmus, descending Ao) diameter measurements were considered to have hypoplasia. Of the 85 patients included in the study, 15 (17\%) had aortic hypoplasia, 10 $(66 \%)$ patients had hypoplasia in the middle of the aortic arch, and $5(33 \%)$ patients in the isthmus. The patients with aortic hypoplasia were treated surgically.

A total of 54 patients underwent surgery, 47 patients in the initial treatment and seven patients in the second treatment. In terms of the preferred surgical technique, $26(48 \%)$ patients were treated with subclavian flap aortoplasty, 24 (44\%) patients with patch plasty, and 4 (7\%) patients with end-to-end anastomosis.

The patients were followed up with a difference in upper-lower limb blood pressure, and echocardiographic evaluation. Because of a difference of $15 \mathrm{mmHg}$ between echocardiographic instantaneous peak pressure gradient and catheter-measured peak-to-peak pressure gradient values of patients who underwent intervention/surgery in clinical practice, an echocardiographic instantaneous peak pressure gradient of $>35 \mathrm{mmHg}$ was taken as reference in the recoarctation evaluation.

Of the treated patients, 17 (28\%) developed recoarctation. It was found that these patients developed recoarctation after a median period of 1.8 years (5 months-4 years). It was found that according to the treatment groups, the median period to the development of recoarctation was 1.4 years ( 7 months- 4 years) in the balloon angioplasty group and 0.9 years (5 months-3.5 years) in the group treated surgically. Considering the treatment groups, there was no significant difference between the post-interventional and surgical treatment follow-up periods in terms of recoarctation development $(\mathrm{p}=0.57)$.

Among the patients followed up after the treatment, $20 \%$ of those who underwent balloon angioplasty developed recoarctation, while $8 \%$ of those who were treated surgically developed recoarctation. Seven patients who underwent stent implantation had no recoarctation throughout the follow-up period. The presence of discrete coarctation $(\mathrm{p}=0.00)$, high pre-procedural peak-to-peak pressure gradient $(\mathrm{p}=0.00)$ and high post-procedural peak-to-peak pressure gradient $(\mathrm{p}=0.00)$, and performing balloon angioplasty $(\mathrm{p}=0.02)$ in the initial treatment were determined to be the factors leading to recoarctation development (Table 3).

Five out of 17 patients who developed recoarctation were followed up without treatment since the difference in upper-lower limb blood pressure was $<20 \mathrm{mmHg}$ and the peak-to-peak pressure gradient was $<20 \mathrm{mmHg}$. In our study, 12 patients were treated for the second time. Before the second treatment, the median instantaneous peak pressure gradient measured by echocardiography was 50 mmHg (range: $40-64 \mathrm{mmHg}$ ). The median time between two treatments was 4 months (range: 3-9 months). In nine of the 25 patients treated with balloon angioplasty in the initial treatment and followed up, surgery was preferred for 7 (36\%) patients and stent implantation for two patients. Of the seven patients who underwent stent implantation in the initial treatment, three were lost to follow-up after the second year and did not require a second treatment during this period, and none of the four patients who were followed up developed recoarctation. In the 27 patients treated surgically in the initial treatment and followed up, balloon angioplasty was used for $3(11 \%)$ patients in the second treatment.

The patients who underwent interventional treatment for the second time had smaller pre-treatment isthmus, descending aorta and coarctation area diameters measured by cardiac catheterization and had higher post-procedural peak-to-peak pressure gradient at the coarctation level compared to those who underwent interventional treatment once $(\mathrm{p}<0.05)$; the pre-treatment $\mathrm{Z}$-scores of the isthmus diameter and descending aorta diameter were not significant.

During this period, a total of 97 treatments were performed on 85 patients, of whom 10 developed procedure-related complications. 
Table 3. Evaluation of patients who developed recoarctation

\begin{tabular}{|c|c|c|c|}
\hline & $\begin{array}{l}\text { Gradient }<35 \mathrm{mmHg}^{*} \\
(\mathrm{n}=39)\end{array}$ & $\begin{array}{l}\text { Gradient }>35 \mathrm{mmHg} \\
(n=17)\end{array}$ & p-value \\
\hline \multicolumn{4}{|l|}{ Age at diagnosis, $\mathrm{n}(\%)$} \\
\hline 1 month-1 year & $19(48.7)$ & $6(35.3)$ & \multirow{2}{*}{0.298} \\
\hline$>1$ year & $10(25.6)$ & $8(47.1)$ & \\
\hline Body weight, median, (IQR) & $6.1(3.8-11.5)$ & $11.0(4.6-21.0)$ & 0.310 \\
\hline Male & $24(61.5)$ & $12(70.6)$ & \multirow{2}{*}{0.516} \\
\hline Female & $15(38.5)$ & $5(29.4)$ & \\
\hline \multicolumn{4}{|l|}{ Location of coarctation, $\mathrm{n}(\%)$} \\
\hline Juxtaductal & $25(64.1)$ & $15(88.2)$ & 0.127 \\
\hline Discrete & $20(51.3)$ & $16(94.1)$ & \multirow{2}{*}{0.002} \\
\hline Tubular & $19(48.7)$ & $1(5.9)$ & \\
\hline \multicolumn{4}{|l|}{ Aortic hypoplasia, n (\%) } \\
\hline Yes & $6(15.4)$ & $2(11.8)$ & \multirow{2}{*}{0.722} \\
\hline No & $33(84.6)$ & $15(88.2)$ & \\
\hline $\begin{array}{l}\text { ECHO peak instantaneous gradient at diagnosis, } \\
(\mathrm{mmHg}) \text {, mean } \pm \mathrm{SD}\end{array}$ & $40.0(28.5-52.5)$ & $45.0(35.0-58.0)$ & 0.276 \\
\hline \multicolumn{4}{|l|}{ Initial procedure type } \\
\hline Balloon & $13(33.3)$ & $12(70.6)$ & \multirow{2}{*}{0.023} \\
\hline Stent & $4^{a}(10.3)$ & 0 & \\
\hline
\end{tabular}

Eight patients who underwent surgical treatment developed minor complications. Of them, six were minor bleeding from the drain that did not require reoperation. Of the patients who developed bleeding, five were in the neonatal period and one was an infant, and two neonates died. Of the patients who underwent stent implantation, one developed femoral artery occlusion which improved with low molecular weight heparin during the follow-up and one developed bleeding, while none of the patients who underwent balloon angioplasty developed early complications. None of the patients developed aneurysm during the follow-up.

\section{Discussion}

Different first-choice treatment options for patients with CoA include interventional and/or surgical procedures. In this study aiming to determine the efficacy, frequency of reinterventions, and associated factors for different firstchoice treatment options, the male/female ratio was 1.8 in line with the literature ${ }^{(3)}$. In our study, the mean age at 
diagnosis was $2.5 \pm 4.1$ years and the median age was 3 months. In their study, Rao et al. ${ }^{(11)}$ reported the mean age at diagnosis as $3.4 \pm 4.3$ years and the mean body weight at the time of diagnosis as $3.5 \pm 0.9 \mathrm{~kg}$ in the surgical group and $3.8 \pm 1 \mathrm{~kg}$ in the balloon angioplasty group. In our study, the body weights of the patients ranged from 2 to $90 \mathrm{~kg}$, and the median body weight at diagnosis was $5 \mathrm{~kg}$ (3-17 kg).

Studies have suggested that the widespread use of fetal echocardiography, knowing that conditions such as enlargement of the right structures on fetal echocardiography may be a warning sign for CoA, increased diagnosis, treatment opportunities, and awareness, makes it possible to diagnose and treat younger and lower weight patients, resulting in a decline in age and body weight at diagnosis.

In our study, the rates of juxtaductal, preductal, and postductal CoAs were $68 \%, 24 \%$, and $7 \%$, respectively. Similarly, in their study on 298 infants, IJsselhof et al. ${ }^{(12)}$ found the rate of juxtaductal discrete coarctation as $40 \%$. Considering the age groups of the patients, $60(70 \%)$ of the 85 patients were infants, and this was associated with an increase in the incidence of aortic hypoplasias and preductal coarctation in these patients.

Numerous studies have reported that the echocardiographic peak instantaneous gradient is correlated with the catheter-measured peak-to-peak pressure gradient in the diagnosis of $\mathrm{CoA}$, but the echocardiographic measurement is higher ${ }^{(13-17)}$. In our study, the peak instantaneous gradient measured in the coarctation area by echocardiography was $45.0 \pm 16.4$ $\mathrm{mmHg}$, and the peak-to-peak pressure gradient measured by cardiac catheterization at the coarctation level was $31.0 \pm 14.7 \mathrm{mmHg}$. In our study, there was a significant difference between the two measurement methods, and the gradient was measured higher by Doppler echocardiography $(\mathrm{p}<0.001)$.

In their study, Rao et al. ${ }^{(11)}$ reported the mean diameter of the coarctation area as $1.7 \pm 0.6 \mathrm{~mm}$ [minimum (min)maximum (max): 0.5-2.8 mm]. In our study, the diameter of the coarctation area was $6.3 \pm 3.4 \mathrm{~mm}$ (min-max: 4.1$8.0 \mathrm{~mm}$ ) in patients with native coarctation, while it was measured as $4.1 \pm 1.4 \mathrm{~mm}$ (min-max: $3.2-5.0 \mathrm{~mm}$ ) in patients with recoarctation before the second procedure.

In patients who require a second treatment and those who do not, studies have reported no significant difference in the Z-score of the isthmus diameter between the two groups ${ }^{(18)}$. In our study results, the Z-scores were $-0.86 \pm 1.34$ and $-0.13 \pm 0.92$, respectively $(p>0.05)$.

In their study on patients younger than one year of age with the diagnosis of CoA, Wood et al. ${ }^{(19)}$ reported that all 181 patients were treated surgically and this number was reported as 83 in the study of Wright et al. ${ }^{(20)}$. Surgical treatment is thought to be used in the foreground since it is technically more challenging to perform interventional treatment methods on neonatal patients, and cardiac anomalies are more common in these patients. In our study, 21 of 23 patients in the neonatal group were treated surgically, and balloon angioplasty was preferred to aid clinical improvement for two patients whose clinics were not suitable for surgical treatment.

In different studies, the peak-to-peak pressure gradient measured after balloon angioplasty treatment has been found as $11.0 \pm 5.0 \mathrm{mmHg}$ and $13.0 \pm 11.0 \mathrm{mmHg}$, which was $8.2 \pm 7.2 \mathrm{mmHg}$ in our study ${ }^{(8,11)}$. In different studies, the peak-to-peak pressure gradient measured after stent treatment was $15.9 \pm 13.4 \mathrm{~mm} \mathrm{Hg}$ and $2.1 \pm 2.4 \mathrm{mmHg}$, which was $2.7 \pm 6.5 \mathrm{mmHg}$ in our study ${ }^{(21,22)}$. In our study, a significant decrease was shown in the peak-to-peak pressure gradient with balloon angioplasty and stent treatments (balloon angioplasty $\mathrm{p}<0.001$, stent $\mathrm{p}=0.02$ ). However, there was no difference between the two treatments $(\mathrm{p}=0.57)$. In patients treated surgically, the peak instantaneous pressure gradient achieved in the distal left subclavian artery decreased from the median value of $40 \mathrm{mmHg}$ [interquartile range (IQR): $30-50.7 \mathrm{mmHg}$ ] to $12 \mathrm{mmHg}$ (IQR: 10-19.2 mmHg) $(\mathrm{p}<0.001)$.

Dijkema et al. ${ }^{(3)}$ reported that they found no difference between the two treatment methods in terms of the decrease in the pressure gradients of 48 patients (19 
balloon angioplasty, 29 surgery) who were treated with balloon angioplasty or surgical technique for $\mathrm{CoA}$ and followed up for an average of 7 years.

A meta-analysis by $\mathrm{Hu}$ et al. ${ }^{(7)}$ comparing balloon angioplasty and surgical treatments for the treatment of CoA evaluated complications that developed in 623 patients (245 balloon angioplasty, 378 surgery) in nine centers, and reported that balloon angioplasty was less invasive, resulting in a reduction in severe complications. When the post-treatment first year was grouped as short term, 1-5 years as midterm, and after 5 years as long term, the risks of post-treatment short-term recoarctation and mid-term and long-term aortic aneurysm were shown to increase significantly.

Given the complications in our study, bleeding was detected in seven patients, including six patients who underwent surgical treatment and one patient who underwent stent implantation, and femoral artery occlusion was detected in one patient who underwent stent implantation. None of the patients who underwent balloon angioplasty developed complications, except for recoarctation. None of the patients developed aneurysm during our follow-up.

The study by Forbes et al. ${ }^{(5)}$ comparing surgery, balloon angioplasty and stent implantation techniques for the treatment of 350 patients with $\mathrm{CoA}$ found the rate of recoarctation development as $19 \%, 32 \%$, and $15 \%$, respectively. In our study, $20 \%$ of patients treated with balloon angioplasty and $8 \%$ of patients who underwent surgery developed recoarctation. None of the patients who underwent stent implantation developed recoarctation.

\section{Conclusion}

The main goals of treatment for CoA are to eliminate coarctation and minimize complications. In untreated CoA patients, it is known that life expectancy is shortened, systemic arterial hypertension develops and progresses more seriously, and mortality and morbidity increase with a decrease in left ventricular function. Early diagnosis and immediate treatment are important to reduce the risk of early and late morbidity and mortality ${ }^{(23)}$.

Interventional treatments are increasingly used for the treatment of CoA compared to surgical treatment. Given the acute complications by treatment preferences in our study, it was found that bleeding was higher in patients who underwent surgical treatment and these patients were especially in the neonatal group. Non-occurrence of any procedure-related complications in patients who underwent balloon angioplasty showed that the procedure could be a more reliable method. However, considering more satisfactory long-term outcomes of surgical treatment, it was concluded that the patient's age, clinical characteristics, and anatomical features of coarctation should be evaluated thoroughly in the treatment selection.

\section{Ethics}

Ethics Committee Approval: This study was approved by the University of Health Sciences Turkey, Dr. Behcet Uz Children's Diseases and Surgery Training and Research Hospital Ethics Committee (decision no: 2018/16-11, date: 08.11.2018).

Informed Consent: It was obtained.

Peer-review: Externally peer-reviewed.

\section{Authorship Contributions}

Surgical and Medical Practices: C.Ö., T.M., M.M.Y., M.K., E.G., C.Z., Concept: C.Ö., T.M., M.M.Y., M.K., E.G., C.Z., Design: C.Ö., T.M., M.M.Y., M.K., E.G., C.Z., Data Collection or Processing: C.Ö., T.M., M.M.Y., M.K., E.G., C.Z., Analysis or Interpretation: C.Ö., T.M., M.M.Y., M.K., E.G., C.Z., Literature Search: C.Ö., T.M., M.M.Y., M.K., E.G., C.Z., Writing: C.Ö., T.M., M.M.Y., M.K., E.G., C.Z.

Conflict of Interest: No potential conflicts of interest relevant to this article was reported.

Financial Disclosure: The authors declared that this study received no financial support. 


\section{References}

1. Reller MD, Strickland MJ, Riehle-Colarusso T, Mahle WT, Correa A. Prevalence of congenital heart defects in metropolitan Atlanta, 1998-2005. J Pediatr 2008;153:807-13.

2. Torok RD, Campbell MJ, Fleming GA, Hill KD. Coarctation of the aorta: Management from infancy to adulthood. World J Cardiol 2015;7:765-75.

3. Dijkema EJ, Sieswerda GT, Takken T, et al. Long-term results of balloon angioplasty for native coarctation of the aorta in childhood in comparison with surgery. Eur J Cardiothorac Surg 2018;53:262-8.

4. Rudolph AM, Heymann MA, Spitznas U. Hemodynamic considerations in the development of narrowing of the aorta. Am J Cardiol 1972;30:514-25.

5. Forbes TJ, Kim DW, Du W, et al. Comparison of surgical, stent, and balloon angioplasty treatment of native coarctation of the aorta: an observational study by the CCISC (Congenital Cardiovascular Interventional Study Consortium). J Am Coll Cardiol 2011;58:2664-74.

6. Brown ML, Burkhart HM, Connolly HM, et al. Coarctation of the aorta: lifelong surveillance is mandatory following surgical repair. J Am Coll Cardiol 2013;62:1020-5.

7. Hu ZP, Wang ZW, Dai XF, et al. Outcomes of surgical versus balloon angioplasty treatment for native coarctation of the aorta: a meta-analysis. Ann Vasc Surg 2014;28:394-403.

8. Ylinen MK, Tyni VE, Pihkala JI, Salminen JT, Sairanen H, Sarkola T. Procedural risk factors, incidence and timing of reintervention after treatment for native coarctation of the aorta in children: a population-based study†. Eur J Cardiothorac Surg 2019;55:564-71.

9. Toro-Salazar OH, Steinberger J, Thomas W, Rocchini AP, Carpenter B, Moller JH. Long-term follow-up of patients after coarctation of the aorta repair. Am J Cardiol 2002;89:541-7.

10. CAMPBELL M, POLANI PE. The aetiology of coarctation of the aorta. Lancet 1961;1:463-8.

11. Rao PS, Chopra PS, Koscik R, Smith PA, Willson AD. Surgical versus balloon therapy for aortic coarctation in infants $<$ or $=3$ months old. J Am Coll Cardiol 1994; 23:1479-83.

12. IJsselhof R, Liu H, Pigula F, et al. Rates of Interventions in Isolated Coarctation Repair in Neonates Versus Infants: Does Age Matter? Ann Thorac Surg 2019;107:180-6.
13. Carvalho JS, Redington AN, Shinebourne EA, Rigby ML, Gibson D. Continuous wave Doppler echocardiography and coarctation of the aorta: gradients and flow patterns in the assessment of severity. Br Heart J 1990;64:133-7.

14. Tan JL, Babu-Narayan SV, Henein MY, Mullen M, Li W. Doppler echocardiographic profile and indexes in the evaluation of aortic coarctation in patients before and after stenting. J Am Coll Cardiol 2005;46:1045-53.

15. Nihoyannopoulos P, Karas S, Sapsford RN, Hallidie-Smith K, Foale R. Accuracy of two-dimensional echocardiography in the diagnosis of aortic arch obstruction. J Am Coll Cardiol 1987;10:1072-7.

16. Cyran SE. Coarctation of the aorta in the adolescent and adult echocardiographic evaluation prior to and following surgical repair. Echocardiography 1993;10:553-63.

17. Seifert BL, DesRochers K, Ta M, et al. Accuracy of Doppler methods for estimating peak-to-peak and peak instantaneous gradients across coarctation of the aorta: An In vitro study. J Am Soc Echocardiogr 1999;12:744-53.

18. Hijazi ZM, Fahey JT, Kleinman CS, Hellenbrand WE. Balloon angioplasty for recurrent coarctation of aorta. Immediate and long-term results. Circulation 1991;84:1150-6.

19. Wood AE, Javadpour H, Duff D, Oslizlok P, Walsh K. Is extended arch aortoplasty the operation of choice for infant aortic coarctation? Results of 15 years' experience in 181 patients. Ann Thorac Surg 2004;77:1353-7.

20. Wright GE, Nowak CA, Goldberg CS, Ohye RG, Bove EL, Rocchini AP. Extended resection and end-to-end anastomosis for aortic coarctation in infants: results of a tailored surgical approach. Ann Thorac Surg 2005;80:1453-9.

21. O'Laughlin MP, Perry SB, Lock JE, Mullins CE. Use of endovascular stents in congenital heart disease. Circulation 1991;83:1923-39.

22. Thanopoulos BD, Giannakoulas G, Giannopoulos A, Galdo F, Tsaoussis GS. Initial and six-year results of stent implantation for aortic coarctation in children. Am J Cardiol 2012;109:1499-503.

23. Attenhofer Jost CH, SchaffHV, Connolly HM, et al. Spectrum of reoperations after repair of aortic coarctation: importance of an individualized approach because of coexistent cardiovascular disease. Mayo Clin Proc 2002;77:64653 